\title{
Reactivity Effects in a Very-High-Temperature Pebble-Bed Reactor
}

\author{
D. M. Pérez ${ }^{1,2^{\star}}$, L. H. Pardo ${ }^{1}$, D. M. Pérez ${ }^{1}$, L. P. R. Garcia ${ }^{2}$, D. E. M. Lorenzo ${ }^{1}$, \\ C. A. B.de Oliveira Lira ${ }^{3}$ \\ ${ }^{I}$ Higher Institute of Technologies and Applied Sciences (InSTEC), University of Havana (UH), \\ Avenida Salvador Allende y Luaces, Quinta de Los Molinos, Plaza de la Revolución, 10400 Havana, Cuba \\ ${ }^{2}$ Universidade Federal de Pernambuco (UFPE), Cidade Universitária, \\ Avenida Professor Luiz Freire, 1000 Recife, PE, Brasil \\ ${ }^{3}$ Centro Regional de Ciências Nucleares $(C R C N-N E)$, Cidade Universitária, \\ Avenida Professor Luiz Freire 200, Recife, PE, Brasil
}

\section{ARTICLE INFO}

Article history:

Received 2 July 2020

Received in revised form 18 August 2020

Accepted 29 August 2020

Keywords:

Very high temperature reactor

Pebble bed reactor

Reactivity effects

MCNP6

VHTR

\begin{abstract}
A B S T R A C T
The very-high-temperature reactor (VHTR) is one of the most promising and innovative designs selected by the Generation IV International Forum. Although previous papers have focused on the study and optimization of several parameter of a VHTR conceptual design, there is still much work needed to achieve the commercial introduction of this technology. The primary aim of this study is to obtain the reactivity effects of such parameters as the temperature of the fuel, moderator, and reflector, and the poisoning by ${ }^{135} \mathrm{Xe}$ and ${ }^{149} \mathrm{Sm}$ in the VHTR critically. To reach this goal, the widely-used MCNP6 code was employed in order to simulate the neutronics of the VHTR. The viability of the utilization of the MCNP6 code and the developed model for the study of the physics of the VHTR core was confirmed through the calculation and comparison with benchmarks provided by the IAEA. Based on the results of the temperature coefficients of reactivity obtained, a negative reactivity effect on the system of about $-12 \mathrm{pcm} / \mathrm{K}$ was found, as is expected in all the nuclear fission reactors, while the combined effect of fission products ${ }^{135} \mathrm{Xe}$ and ${ }^{149} \mathrm{Sm}$ implies a negative reactivity of $-3475 \mathrm{pcm}$.
\end{abstract}

(C) 2021 Atom Indonesia. All rights reserved

\section{INTRODUCTION}

Presently, a new generation of nuclear reactors, the Generation IV, is being developed under stringent requirements of safety and reliability, proliferation resistance and physical protection, economics, and sustainability. Among the systems identified for this new generation, the very-high-temperature reactor (VHTR) stands out as one of the most promising future reactor concepts [1-4]. The VHTR is the next generation in the technological development of high temperature reactors using ceramic fuel, graphite as a moderator, and helium gas as a coolant. It is based on the experience from a group of experimental and commercial high-temperature gas-cooled reactors (HTGR) built and operated during the second half of

${ }^{*}$ Corresponding author

E-mail address: daniel.milian@ufpe.br

DOI: https://doi.org/10.17146/aij.2021.1075 the $20^{\text {th }}$ century and two current projects. The former consist of Dragon in the United Kingdom (1964-1975), Peach Bottom (1966-1989) and Fort St. Vrain (1976-1989) in the United States, and AVR (1967-1988) and THTR (1985-1991) in Germany. The latter are the HTTR-2000 in Japan and the HTR-10 in China, which became operational in the years 2000 and 2003, respectively. In addition, the HTR-PM, planned to be the world's first high-temperature gas-cooled reactor pebble-bed module demonstration power plant, is under construction since 2012 at the Shidao Bay site in Rongcheng, Shandong Province, China [5]. The successful operation of these reactors highlighted the feasibility of the encapsulated fuel technology, as well as the advantages of using a gas as coolant $[1,3,6,7]$. The main difference between the VHTR and the preceeding HTGR lays in higher core outlet temperatures, which allows a significant increase in the thermal efficiency of the power plant, 
over $50 \%$ at $1000{ }^{\circ} \mathrm{C}$ [1]. That higher outlet temperature, although it will require the development and qualification of innovative materials such as new super alloys, ceramics and compounds, will allow large-scale bulk hydrogen production with the iodine-sulphur (I-S) process $[2,3,8,9]$.

In the two decades that have passed, since the establishment of the Generation IV International Forum (GIF) in 2000, various VHTR projects or conceptual designs have been studied, allowing the establishment of the theoretical basis for the implementation of this technology. However, the commercial deployment of this technology is still facing key challenges in a group of areas. It has been identified that substantial research, development, and demonstration of systems' conceptual/detailed design and analysis are needed [3], especially focused on what refers to enhancing the nuclear safety characteristics. For that purpose, the refurbishment of old experimental facilities and/or the construction of new experimental facilities, which tend to be increasingly complex and costly, will be necessary. The use of computational codes, for the comprehensive computational simulation of the complex processes and phenomena that occur in these systems, provide a cost effective and accurate initial alternative to scale model testing. At the same time, it reduces the number of new experimental facilities and tests required during the experimental testing phase.

Therefore, this paper delves into the study of issues related to the nuclear safety characteristics of an VHTR conceptual design. The primary aim of this study is to obtain the reactivity effects of such parameters as the fuel, moderator (graphite), and reflector (graphite) temperatures and the poisoning by ${ }^{135} \mathrm{Xe}$ and ${ }^{149} \mathrm{Sm}$ in the VHTR critically. The reactivity effects of the variation of the coolant (helium) temperature was not taken into consideration as helium is essentially transparent to thermal neutrons. To reach this goal, the widely used MCNP6 code [10] was employed in order to simulate the neutronics of the VHTR.

In the Theory section, a brief portrayal of the VHTR conceptual design studied in this paper and the HTR-PROTEUS and ASTRA critical facilities (used for validation purposes) is presented. In the Methodology section, a brief description of the MCNP6 code, the calculations tasks and the control parameters used for the calculations is presented. In the Validation section, the experimental results of the benchmark tasks, reported in the IAEATECDOC-1249 [11] and the IAEA-TECDOC-1694 [12] for the HTR-PROTEUS and ASTRA critical facilities, respectively and the results obtained with the MCNP6 code and are discussed and compared. Finally, in the Results and Discussion section, the calculations results of the reactivity effects of the parameters fuel, moderator (graphite) and reflector (graphite) temperatures and the poisoning by ${ }^{135} \mathrm{Xe}$ and ${ }^{149} \mathrm{Sm}$ in the VHTR critically are presented and discussed.

\section{THEORY}

The proposed reactor conceptual design is a pebble bed gas-cooled and graphite moderated VHTR, defined and optimized in previous studies [13-15]. The main parameters of the VHTR model are presented in Table 1. Figures 1 and 2 show the longitudinal and cross-sectional views of the VHTR geometrical model on the MCNP Visual Editor. The fuel in the reactor's core is composed by TRISO coated particles confined in approximately 263 465 pebbles. Each pebble contains approximately 4.5 grams of $\mathrm{UO}_{2}$ enriched to $6 \%$ in ${ }^{235} \mathrm{U}$. The $\mathrm{UO}_{2}$ mass composition in each fuel pebble is presented in Table 2. Both in the validation and in the VHTR conceptual design calculations, the TRISO fuel was represented as a homogeneous mixture inside the fuel elements, while the fuel elements were distributed orderly in the core using a body-centered cubic (BCC) arrangement [16].

Table 1. Main parameters of the VHTR

\begin{tabular}{ll}
\hline Parameter & Value \\
\hline Power (MWth) & 200 \\
Core height $(\mathrm{m})$ & 2.9394 \\
Core diameter $(\mathrm{m})$ & 4.175 \\
Core volume $\left(\mathrm{m}^{3}\right)$ & 40.24 \\
Fuel volume $\left(\mathrm{m}^{3}\right)$ & 6547 \\
Number of pebbles & 263465 \\
Burnable poison & None \\
Average power density $\left(\mathrm{MWth} / \mathrm{m}^{3}\right)$ & 5 \\
Packing fraction & 0.74 \\
Reflector thickness $(\mathrm{m})$ & 1.80 \\
\hline
\end{tabular}

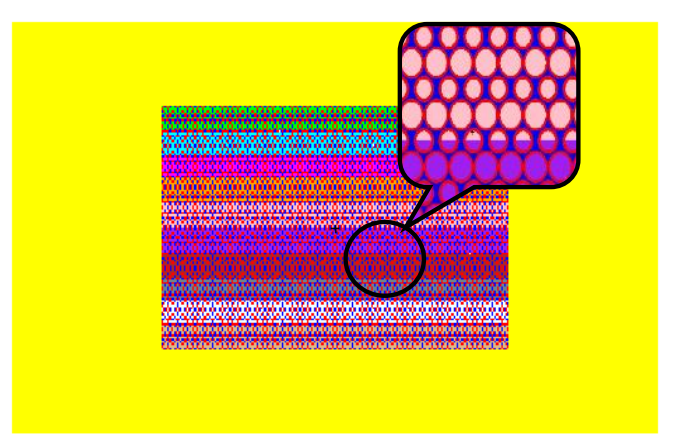

Fig. 1. Longitudinal section of the VHTR geometrical model on the MCNP Visual Editor 


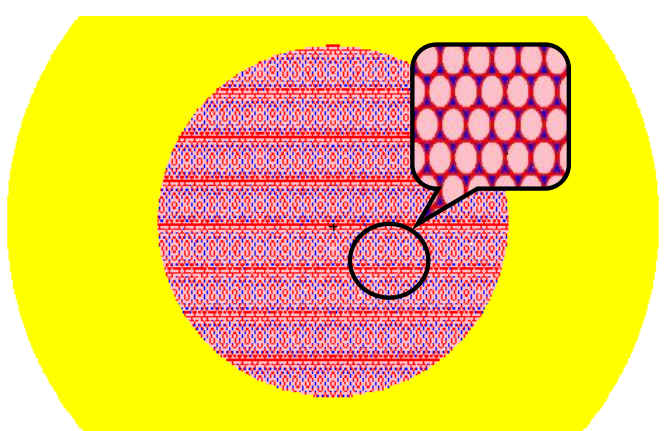

Fig. 2. Cross-section of the VHTR geometrical model on the MCNP Visual Editor

Table 2. Mass composition of the fuel pebbles

\begin{tabular}{cc}
\hline Isotope & Mass (grams) \\
\hline${ }^{235} \mathrm{U}$ & 0.238 \\
${ }^{238} \mathrm{U}$ & 3.728 \\
${ }^{16} \mathrm{O}$ & 0.534 \\
\hline
\end{tabular}

The HTR-PROTEUS system [11] (Figs. 3 and 4) can be described as a hollow cylinder of graphite, $330.4 \mathrm{~cm}$ in height and $326.2 \mathrm{~cm}$ in diameter (used as reflector). Inside the hollow cylinder, there is a central cavity with base $78 \mathrm{~cm}$ above the bottom of the lower axial reflector and having a horizontal cross-section in the form of a 22 sided polygon with a flat-to-flat separation of $125 \mathrm{~cm}$. The cavity contains fuel and moderator pebbles, either randomly arranged or in one of several different geometrical arrangements. Each pebble contains approximately 5.966 grams of $\mathrm{UO}_{2}$ enriched to $16.7 \%$ in ${ }^{235} \mathrm{U}$. An aluminum "safety ring" located $176.4 \mathrm{~cm}$ above the floor of the cavity prevents the upper axial reflector from falling onto the pebble-bed in the case of an accident. The reactivity control is achieved by means of four fine control rods at a radius of $90 \mathrm{~cm}$, while for the shutdown of the reactor are used four boron-steel rods situated at a radius of $68 \mathrm{~cm}$.

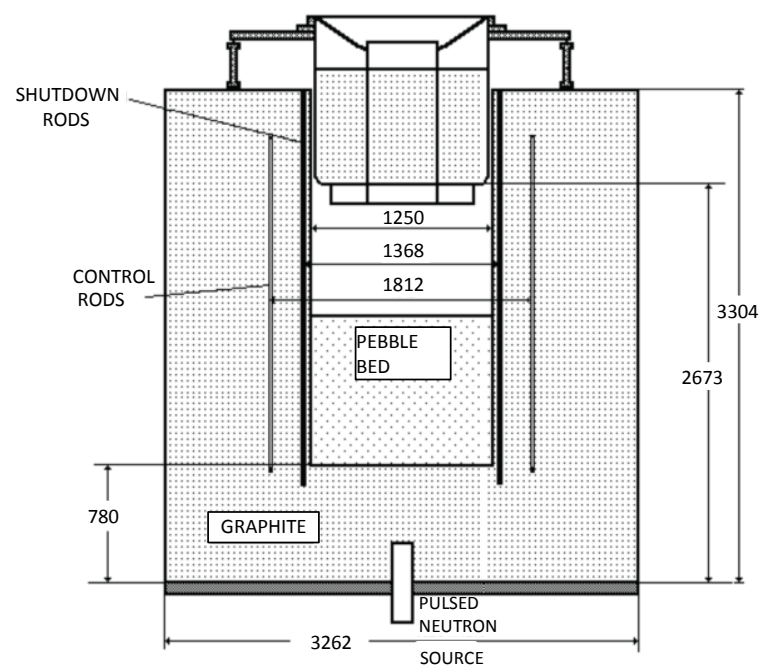

Fig. 3. Longitudinal schematic view of the core region of the HTR-PROTEUS (dimensions in $\mathrm{mm}$ )

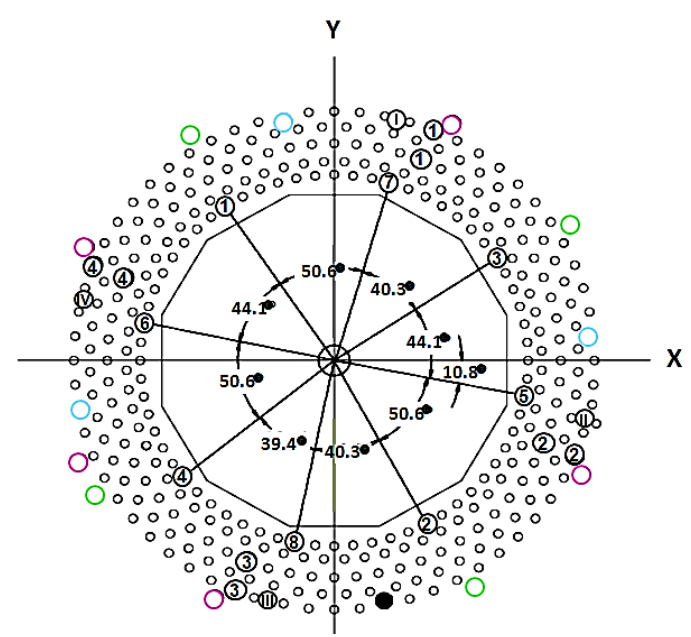

Fig. 4. Cross-sectional schematic view of the core region of the HTR-PROTEUS

The ASTRA critical facility [12] (Figs. 5 and 6) consists of an upright circular graphite cylinder with an outer diameter of $380 \mathrm{~cm}$, an equivalent inner diameter of $181 \mathrm{~cm}$, and a height of $460 \mathrm{~cm}$. This graphite structure, which serves as radial and bottom reflector, surrounds an octagonal core located $40 \mathrm{~cm}$ above the bottom reflector.

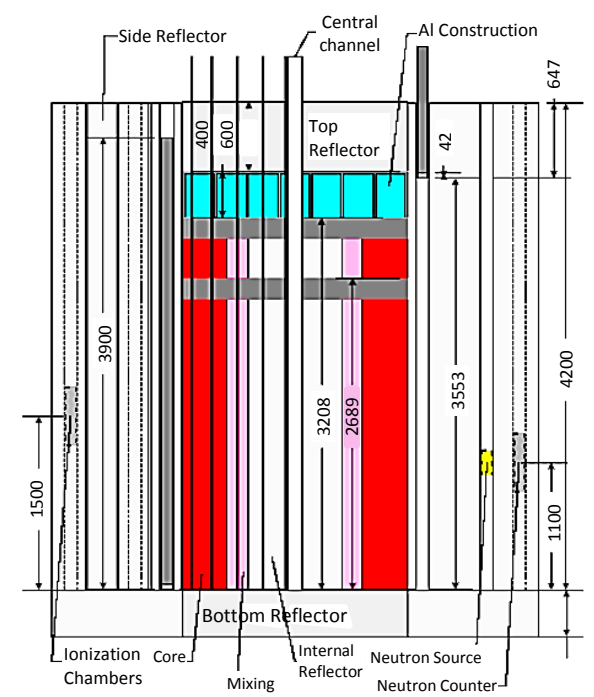

Fig. 5. Longitudinal schematic view of the core region of the ASTRA (dimensions in $\mathrm{mm}$ )

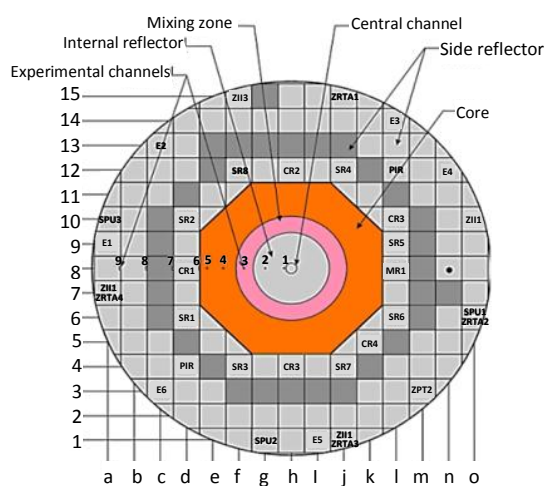

Fig. 6. Cross-sectional schematic view of the core region of the ASTRA 
The core is divided into three zones, an inner reflector zone, a mixed fuel and moderator zone and an outer fuel zone. These three zones are loaded stochastically with spherical elements with a diameter of $6 \mathrm{~cm}$. Three types of spherical elements were employed namely, Fuel Spheres (FS), Absorber Spheres (AS) and Graphite Spheres (Moderator Spheres - MS). The fuel and absorber spheres consist of a central sphere containing the fuel/absorber material in a graphite matrix surrounded by a graphite shell. Each FS contains approximately 2.44 grams of $\mathrm{UO}_{2}$ enriched to $21.0 \%$ in ${ }^{235} \mathrm{U}$. A packing ratio of 0.625 was assumed. The control rods (CR), safety rods (SR), and manual rod (MR) in the ASTRA critical facility are situated in the side reflector inside the axial channels of the graphite blocks.

The description contained in this section about the HTR-PROTEUS and ASTRA critical facilities serves only to give a brief qualitative picture of the facilities. Full details of the facilities, for use in the benchmarking of codes and data, including atom densities, can be found elsewhere [11,12] and are not included here for reasons of space.

\section{METHODOLOGY}

The MCNP6 [10] is a computational code based on Monte Carlo probabilistic method for computer modeling of time-dependent transportation of many types of particles for different geometries and a wide range of energies. The statistical nature of the process is based on generating random numbers to form histories. These random numbers represent each logical event that neutrons may experience and the study of the neutron trajectory from its birth until its capture or escape (neutron history). The neutronic analysis developed in this work is as follows:

1. Calculate the IAEA benchmarks announced by the IAEA-TECDOC-1249 [11] and the IAEATECDOC-1694 [12] for the HTR-PROTEUS and ASTRA critical facilities. Compare the reactor physics experimental parameters: effective multiplication coefficient $\left(K_{e f f}\right)$ and worth of control rods with the calculated values with MCNP6.

2. Calculate the reactivity effect due to variations of fuel, moderator (graphite), and reflector (graphite) temperatures for five burnup states of the VHTR conceptual design.

3. Calculate the reactivity effect due to poisoning by ${ }^{135} \mathrm{Xe}$ and ${ }^{149} \mathrm{Sm}$.

The MCNP6 code calculations were performed on a personal computer (operating system: Microsoft Windows 64 bit, 8 cores,
16 GB Memory). The control parameters used for the MCNP6 calculations were the following:

Source size per cycle: 2000

Initial guess for K-infinite: 1.0

Number of settle cycles: 50

Total cycles to run: 1050

Total histories: 2000000

The fuel temperature coefficient of reactivity (FTC) was evaluated using continuous-energy neutron data libraries from ENDF/B-VII.1, ENDF/B-VII.0 and ENDF/B-VI.2 evaluations released in 2011, 2006, and 1993, respectively. The moderator (MTC) and reflector (RTC) temperature coefficients of reactivity were only evaluated using libraries from ENDF/B-VII.1. Tables 3 and 4 show the temperatures studied for the fuel, moderator, and reflector. Thermal neutrons were suitably described by both the free gas treatment, with TMP card, and $S(\alpha, \beta)$ models for materials containing graphite nuclei at the corresponding temperature. For each component, the temperature coefficient was calculated by varying its temperature and keeping that of the others constant at $293.6 \mathrm{~K}$, at different burnup states. The $K_{\text {eff }}$ of the system for each temperature and burnup states was used to calculate the reactivity $\rho[\mathrm{pcm}]$ by means of $10^{5} \times\left(K_{\text {eff }}-1\right) / K_{\text {eff. }}$. The $\rho(T)$ points for each burnup state were fitted to a quadratic curve using the least squares method. Using the temperature coefficient of reactivity definition [17]:

$$
\alpha_{T}=\frac{\partial \rho(T)}{\partial T}
$$

the coefficient was obtained as a linear function of temperature:

$$
\alpha_{T}(T)[p c m / K]=a T[K]+b
$$

where $a$ and $b$ are constants. Furthermore, the $\rho(T)$ points were linearly fitted in order to obtain a representative constant value of the coefficient in the temperature range studied for each burnup state.

For evaluating the reactivity effects of the poisoning by ${ }^{135} \mathrm{Xe}$ and ${ }^{149} \mathrm{Sm}$, burnup calculations were made taking into consideration the ${ }^{135} \mathrm{Xe}$ and ${ }^{149} \mathrm{Sm}$ production and without taking into consideration the ${ }^{135} \mathrm{Xe}$ and ${ }^{149} \mathrm{Sm}$ production using the OMIT card during the MCNP6 calculation.

Table 3. Library names and temperatures analyzed for the fuel

\begin{tabular}{cccc}
\hline Temp (K) & ENDF71x & endf70 & endf62 mt \\
\hline 293.6 & $80 \mathrm{c}$ & $70 \mathrm{c}$ & - \\
400 & - & - & $12 \mathrm{c}$ \\
500 & - & - & $13 \mathrm{c}$ \\
600 & $81 \mathrm{c}$ & $71 \mathrm{c}$ & $14 \mathrm{c}$ \\
800 & - & - & $15 \mathrm{c}$ \\
900 & $82 \mathrm{c}$ & $72 \mathrm{c}$ & $16 \mathrm{c}$ \\
1200 & $83 \mathrm{c}$ & $73 \mathrm{c}$ & $17 \mathrm{c}$ \\
\hline
\end{tabular}


Table 4. Libraries and temperatures analyzed for the moderator and reflector

\begin{tabular}{cc}
\hline Temperature $(\mathbf{K})$ & ENDF71x \\
\hline 293.6 & $80 \mathrm{c}$ \\
600 & $81 \mathrm{c}$ \\
900 & $82 \mathrm{c}$ \\
1200 & $83 \mathrm{c}$ \\
\hline
\end{tabular}

\section{Validation}

The results of experiments conducted in the critical facilities HTR-PROTEUS [11] and ASTRA [12] were used to evaluate the viability of the utilization of the MCNP6 code and the developed model for the study of the physics of the VHTR conceptual design.

For the HTR-PROTEUS the calculated results of the $K_{\text {eff }}$ and control rod worth for thirteen configurations of the core were compared with the experimental values. Table 5 shows the calculated and measured values of $K_{\text {eff }}$ for each configuration, as well as the relative difference between these values and the experimental $K_{\text {eff. }}$ The $K_{\text {eff }}$ standard deviation ranged from 0.00009 to 0.00011 for all the performed calculations. Table 6 shows the calculated and measured values of control rod worth for four configurations of the core, as well as the relative difference between these values.

Table 5. Calculated and measured values of $K_{\text {eff }}$ for 13 configurations of the HTR-PROTEUS core

\begin{tabular}{cccc}
\hline $\begin{array}{c}\text { Core } \\
\text { Configuration }\end{array}$ & $\begin{array}{c}\text { Experimental } \\
\boldsymbol{K}_{\text {eff }}\end{array}$ & $\begin{array}{c}\text { Calculated } \\
\boldsymbol{K}_{\text {eff }}\end{array}$ & $\begin{array}{c}\text { Difference } \\
\boldsymbol{\%}\end{array}$ \\
\hline $1 \mathrm{~A}$ & 1.0147 & 1.0172 & 0.25 \\
2 & 1.0106 & 1.0154 & 0.47 \\
3 & 1.0033 & 1.0041 & 0.08 \\
$4(1)$ & 1.0134 & 1.0168 & 0.33 \\
$4(2)$ & 1.0129 & 1.0138 & 0.09 \\
$4(3)$ & 1.0132 & 1.0257 & 1.23 \\
5 & 1.0112 & 1.0145 & 0.32 \\
6 & 1.0075 & 1.0100 & 0.25 \\
7 & 1.0067 & 1.0113 & 0.45 \\
8 & 1.0160 & 1.0230 & 0.69 \\
$9(1)$ & 1.0062 & 1.0158 & 0.96 \\
$9(2)$ & 1.0142 & 1.0312 & 1.67 \\
10 & 1.0075 & 1.0142 & 0.67 \\
\hline
\end{tabular}

Table 6. The integral worth of the control rods in dollar cents, in core $7,1 \$=727 \mathrm{pcm}$, in the other cores $1 \$=720 \mathrm{pcm}$

\begin{tabular}{|c|c|c|c|c|}
\hline \multirow{2}{*}{ Rods } & \multicolumn{2}{|r|}{ Core 5} & \multicolumn{2}{|r|}{ Core 7} \\
\hline & Exp. & Calc. & Exp. & Calc. \\
\hline 1 & 36.03 & $35.17(-2.39 \%)$ & 21.76 & $21.55(-0.97 \%)$ \\
\hline 2 & 36.03 & $35.44(-1.64 \%)$ & 21.69 & $21.15(-2.49 \%)$ \\
\hline 3 & 36.03 & $34.98(-2.91 \%)$ & 21.60 & $21.22(-1.76 \%)$ \\
\hline 4 & 36.03 & $35.27(-2.11 \%)$ & 22.02 & $21.37(-2.95 \%)$ \\
\hline SUM & 134.0 & $140.9(-2.26 \%)$ & 87.1 & $85.3(-2.04 \%)$ \\
\hline \multirow{2}{*}{ Rods } & \multicolumn{2}{|r|}{ Core 9} & \multicolumn{2}{|r|}{ Core 10} \\
\hline & Exp. & Calc. & Exp. & Calc. \\
\hline 1 & 39.69 & $38.52(-2.95 \%)$ & 28.19 & $27.64(-1.95 \%)$ \\
\hline 2 & 39.04 & $38.06(-2.51 \%)$ & 27.85 & $26.95(-3.23 \%)$ \\
\hline 3 & 39.07 & $38.88(-0.49 \%)$ & 27.64 & $27.33(-1.12 \%)$ \\
\hline 4 & 39.61 & $38.96(-1.64 \%)$ & 28.15 & $27.15(-3.55 \%)$ \\
\hline SUM & 157.4 & $154.4(-1.90 \%)$ & 111.8 & $109.1(-2.47 \%)$ \\
\hline
\end{tabular}

As seen in Table 5, the calculations results obtained for the $K_{\text {eff }}$ present a good agreement with the experimental values. The $K_{\text {eff }}$ calculation result with greatest discrepancy regarding the experimental value is for the core configuration 9(2), which has a relative difference of $1.67 \%$, which can be considered acceptable, keeping in mind that the investigations on the VHTR are in a stage of conceptual design. The comparison between the calculated and experimental integral worth of the control rods also present a good agreement. The largest discrepancy is for the control rod 4 of core configuration $10(-3.55 \%)$. As noted in Table 5 , the calculated $K_{\text {eff }}$ always predicts a higher value than the experimental one. This result is consistent with the results obtained for the integral worth of the control rods, which for all the cases studied underpredict the worth of the control rods.

For the ASTRA, a set of four calculational benchmark problems were solved. The first calculational benchmark problem included the determination of the critical height for a given core loading, increasing the height of the pebble bed core until criticality was reached. The experimental critical pebble bed height obtained at the ASTRA critical facility was $268.9 \pm 0.15 \mathrm{~cm}$. The second calculational benchmark problem investigated the total reactivity worth of control rods depending on their position in the side reflector as well as the effect of a system of two or three control rods. The third calculational benchmark problem evaluated the differential reactivity worth of a control rod depending on the depth of its insertion. Finally, the fourth calculational benchmark problem investigated the reactivity effect of varying the core height.

For the first calculational benchmark problem, $K_{\text {eff }}$ was obtained modifying the pebble bed height from $227.80 \mathrm{~cm}$ to $308.14 \mathrm{~cm}$. Table 7 shows the calculation results of $K_{\text {eff }}$ vs. pebble bed height. A critical height of $268.66 \mathrm{~cm}$ was determined by interpolation. This value has a relative difference of $0.089 \%$ with respect to the experimental value.

Table 7. $K_{\text {eff }}$ vs. pebble bed height

\begin{tabular}{ccc}
\hline Pebble bed height $(\mathbf{c m})$ & $\boldsymbol{K}_{\text {eff }}$ & Standard Deviation \\
\hline 227.80 & 0.96850 & 0.00029 \\
236.72 & 0.97614 & 0.00029 \\
245.65 & 0.98374 & 0.00028 \\
254.58 & 0.99032 & 0.00029 \\
263.50 & 0.99728 & 0.00030 \\
272.43 & 1.00265 & 0.00029 \\
281.36 & 1.00734 & 0.00029 \\
290.28 & 1.01269 & 0.00028 \\
299.21 & 1.01688 & 0.00029 \\
308.14 & 1.02193 & 0.00029 \\
\hline
\end{tabular}


The objective of the first task of the second calculational benchmark problem was obtaining the total reactivity worth of the individual control rods CR2 and CR4 depending on their position in the side reflector. The comparison between the calculated worth of the control rods using the $K_{\text {eff }}$ values obtained with MCNP6 and the worth experimentally obtained at the ASTRA critical facility are shown in Table 8 . The second task was investigating the worth for different control rod combinations and the interference effect of a system of control rods. Results for these parameters are shown in Tables 9 and 10 .

Table 8. Total reactivity worth of the individual control rods CR2 and CR4

\begin{tabular}{lcccc}
\hline \multirow{2}{*}{ CR } & \multirow{2}{*}{ Position } & \multicolumn{3}{c}{ Reactivity Worth (\$) } \\
\cline { 3 - 5 } & & Experiment & Calculated & Difference \% \\
\hline CR2 & h12 & -2.550 & -2.528 & -0.86 \\
CR2 & h13 & -0.880 & -0.871 & -1.02 \\
CR2 & h14 & -0.220 & -0.217 & -1.36 \\
CR2 & h15 & -0.030 & -0.029 & -2.00 \\
CR4 & k5 & -1.950 & -2.897 & -2.72 \\
CR4 & 14 & -0.340 & -0.337 & -0.88 \\
\hline
\end{tabular}

Table 9. Worth for different control rod combinations

\begin{tabular}{cccc}
\hline \multirow{2}{*}{$\begin{array}{c}\text { CR } \\
\text { combinations }\end{array}$} & \multicolumn{3}{c}{ Reactivity Worth $\mathbf{( \$ )}$} \\
\cline { 2 - 4 } & Experiment & Calculated & $\begin{array}{c}\text { Difference } \\
\text { \% }\end{array}$ \\
\hline CR1+CR5 & -5.160 & -5.188 & 0.54 \\
CR2+CR5 & -5.570 & -5.513 & -1.03 \\
CR4+CR5 & -4.310 & -4.293 & -0.39 \\
CR1+CR2+CR5 & -8.420 & -8.396 & -0.29 \\
CR1+CR4+CR5 & -7.150 & -7.074 & -1.06 \\
CR2+CR4+CR5 & -7.570 & -7.493 & -1.02 \\
\hline
\end{tabular}

The results obtained with the MCNP6 code, for the total reactivity worth of the individual control rods (CR2 and CR4) in the six positions studied, are lower than the experimental values. The result with the greatest discrepancy regarding the experimental value $(-2.72 \%)$ was for the control rod $\mathrm{C} 4$ at position k5. For the worth and interference effect for different control rod combinations the differences with the experimental values are below $-1.06 \%$ and $6.42 \%$, respectively. Only the control rod combination CR1+CR5 give results that overpredict reactivity worth relative to the experimental result; the rest of the combinations studied underpredict the reactivity worth.

Table 10. Interference effect for different control rod combinations

\begin{tabular}{cccc}
\hline \multirow{2}{*}{ CR combinations } & \multicolumn{3}{c}{ Interference effect } \\
\cline { 2 - 4 } & Experiment & Calculated & $\begin{array}{c}\text { Difference } \\
\text { \% }\end{array}$ \\
\hline CR1+CR5 & 1.030 & 1.077 & 4.57 \\
CR2+CR5 & 1.090 & 1.160 & 6.42 \\
CR4+CR5 & 0.960 & 0.975 & 1.52 \\
CR1+CR2+CR5 & 1.110 & 1.155 & 4.04 \\
CR1+CR4+CR5 & 1.030 & 1.035 & 0.52 \\
CR2+CR4+CR5 & 1.070 & 1.082 & 1.08 \\
\hline
\end{tabular}

The objective of the third calculational benchmark problem was obtaining the reactivity worth of two control rods (CR5 and MR1) for several insertion heights. The results of the calculations and the experimental measurements of the reactivity worth at several insertion heights are shown in Figs. 7 and 8, respectively.

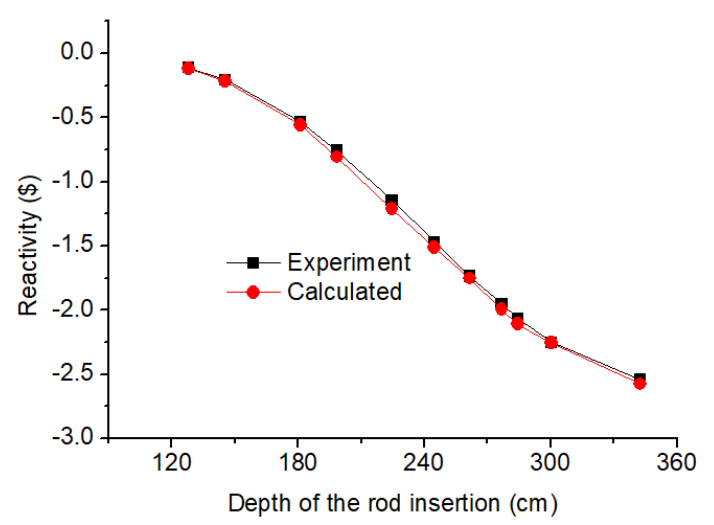

Fig. 7. Differential worth of ASTRA control rod CR5

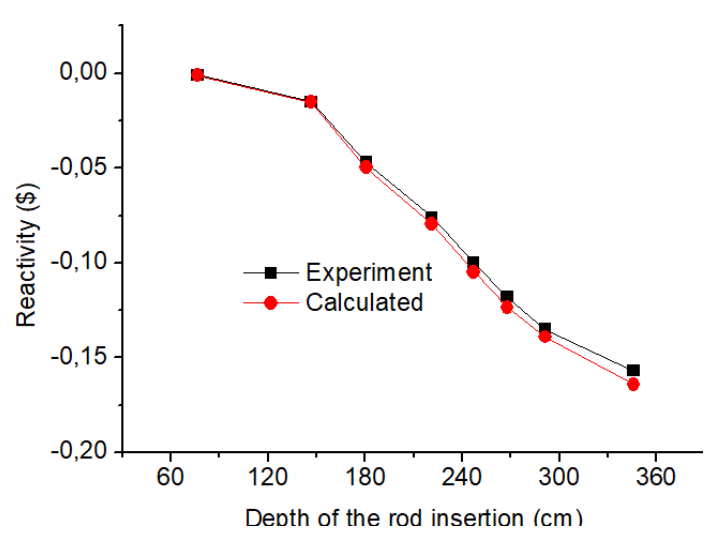

Fig. 8. Differential worth of ASTRA manual rod MR1

The results of the calculations using MCNP6 overpredict the differential reactivity worth of the control rods CR5 and MR1. The result with the greatest absolute difference with the experimental value $(-0.07 \$)$ was the one for the control rod CR5 at an insertion height of $224.7 \mathrm{~cm}$. As observed in Figs. 7 and 8, the curves' behavior is quite similar to the experimental curves.

Table 11. Variation in the reactivity margin with increasing height

\begin{tabular}{ccccc}
\hline Conf. & $\begin{array}{c}\text { Height } \\
\mathbf{( c m )}\end{array}$ & $\begin{array}{c}\text { Experiment } \\
\mathbf{( \$ )}\end{array}$ & $\begin{array}{c}\text { Calculated } \\
\mathbf{( \$ )}\end{array}$ & $\begin{array}{c}\text { Difference } \\
\mathbf{\%}\end{array}$ \\
\hline 1 & 268.9 & $0.10 \pm 0.01$ & 0.11 & 14.00 \\
2 & 274.4 & $0.64 \pm 0.01$ & 0.67 & 4.22 \\
3 & 281.4 & $1.14 \pm 0.01$ & 1.18 & 3.07 \\
4 & 285.9 & $1.58 \pm 0.01$ & 1.60 & 1.52 \\
5 & 291.8 & $2.01 \pm 0.02$ & 2.14 & 6.32 \\
6 & 297.4 & $2.43 \pm 0.02$ & 2.55 & 4.94 \\
7 & 303.5 & $2.85 \pm 0.02$ & 2.92 & 2.60 \\
8 & 309.4 & $3.26 \pm 0.02$ & 3.33 & 2.27 \\
9 & 315.2 & $3.66 \pm 0.02$ & 3.76 & 2.68 \\
10 & 320.8 & $4.03 \pm 0.02$ & 4.15 & 2.95 \\
\hline
\end{tabular}


Finally, the fourth calculational benchmark problem was performed representing different pebble bed heights in order to determine the change in reactivity due to an increase in the height of the ASTRA critical assembly pebble bed. The heights considered and the experimental and calculational results are shown in Table 11. As expected, there is an almost linear increase in the reactivity margin with the increase of the pebble bed height. The height with the greatest relative difference with respect to the experimental value is located at $268.9 \mathrm{~cm}$.

In summary, the results presented in this section about the MCNP6 utilization for the computational simulation of VHTR by means of the resolution of the IAEA benchmarks confirm the viability of the utilization of this computational code and the computational models developed for the study of pebble bed gas-cooled and graphite moderated advanced nuclear systems.

\section{RESULTS AND DISCUSSION}

The reactivity effect due to variations in fuel, moderator (graphite), and reflector (graphite) temperatures was studied for the VHTR conceptual design. The calculations of the reactivity effect due to variations in the fuel temperature were done for five fuel burnup states: $0,6.32,12.64,18.96$, and $25.28 \mathrm{GWd} / \mathrm{tU}$, which correspond to four intervals of 33 days each and a thermal power of $200 \mathrm{MW}_{\text {th. }}$.

Figures 9, 10, and 11 show the evolution of the reactivity with the increase of the temperature of the fuel, moderator and reflector, respectively, calculated with the ENDF71x library. Quadratic curves were fitted to those $\rho(T)$ points for each burnup state and represented by dash lines. By simply examining the graphs, it is clearly seen that FTC and MTC are negative, while RTC is positive in the temperature range studied.

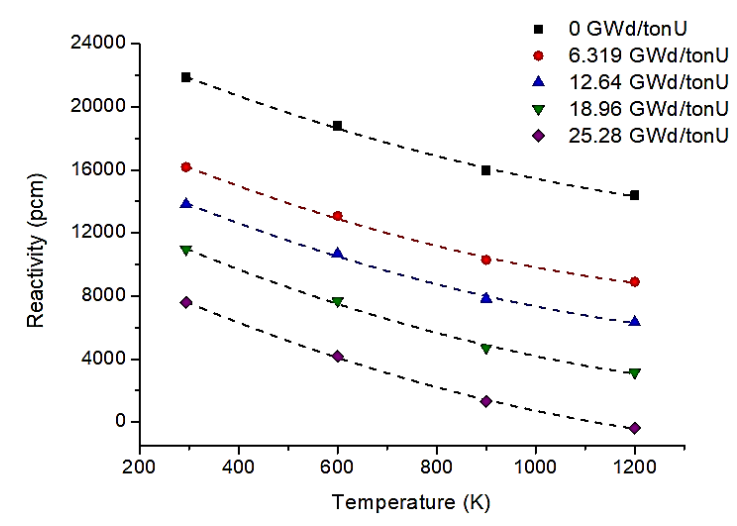

Fig. 9. Evolution of the reactivity with the increase of the temperature of the fuel

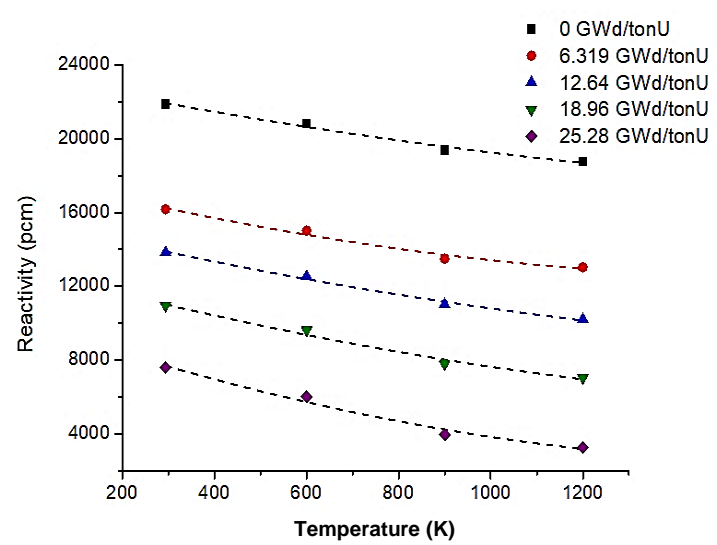

Fig. 10. Evolution of the reactivity with the increase of the temperature of the moderator

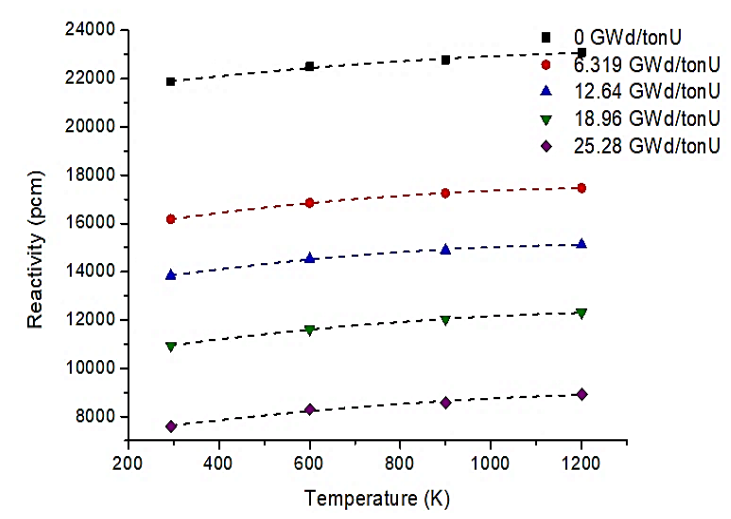

Fig. 11. Evolution of the reactivity with the increase of the temperature of the reflector

Table 12 shows the FTC calculated for the five fuel burnup states, represented in two forms: a linear dependence on temperature where the constants of Eq. [2] are given, and a constant value (between $-9 \quad \mathrm{pcm} / \mathrm{K}$ and $-8 \quad \mathrm{pcm} / \mathrm{K}$ ) that is representative (average) for the temperature range studied. Also, the FTC values calculated using three nuclear data libraries are shown. FTC constant values calculated with endf70 libraries do not differ much from those obtained with ENDF71x, they agree within $1.5 \%$ for all burnup states. In the case of endf62mt, the differences with respect to ENDF71x results ranges from $7 \%$ to $11 \%$. The good agreement between ENDF71x and endf70 data libraries is not the same between ENDF71x and endf62mt, which is reasonable considering that endf62mt libraries were processed from data evaluated more than two decades ago, they are not available for all isotopes constituting the materials and they do not consider some important events such as the production of delayed neutrons. The results obtained with ENDF71x libraries were assumed as the reference ones for this paper and from now on, the reported results refer to those obtained with that libraries. 
Table 12. FTC for the six burnup states calculated by two approaches

\begin{tabular}{ccccccccccc}
\hline \multirow{2}{*}{$\begin{array}{c}\text { Burnup state } \\
\text { (GWd/tU) }\end{array}$} & \multicolumn{4}{c}{$\begin{array}{c}\text { Linear dependence on temperature } \\
\text { (constants for equation 2) }\end{array}$} & \multicolumn{3}{c}{ Constant value (pcm/K) } \\
\cline { 2 - 10 } & \multicolumn{2}{c}{ ENDF71x } & \multicolumn{2}{c}{ endf70 } & \multicolumn{2}{c}{ endf62mt } & ENDF71x & endf70 & endf62mt \\
\cline { 2 - 10 } & $\boldsymbol{a}$ & $\boldsymbol{b}$ & $\boldsymbol{a}$ & $\boldsymbol{b}$ & $\boldsymbol{a}$ & $\boldsymbol{b}$ & & \\
\hline 0 & 0.00788 & -14.2692 & 0.00660 & -13.2173 & 0.00708 & -13.1552 & -8.3808 & -8.2968 & -7.5228 \\
6.319 & 0.00910 & -14.9585 & 0.00810 & -14.2157 & 0.00808 & -13.9383 & -8.1684 & -8.1733 & -7.5041 \\
12.64 & 0.00884 & -15.0019 & 0.00868 & -14.8518 & 0.00876 & -14.7651 & -8.4015 & -8.3780 & -7.7847 \\
18.96 & 0.00898 & -15.4624 & 0.00864 & -15.1444 & 0.00830 & -14.5860 & -8.7592 & -8.7000 & -7.9841 \\
25.28 & 0.00904 & -15.6433 & 0.00984 & -16.1166 & 0.00928 & -15.6407 & -8.9007 & -8.7722 & -8.2467 \\
\hline
\end{tabular}

The FTC values go from about $-12.5 \mathrm{pcm} / \mathrm{K}$ for $293.6 \mathrm{~K}$ to about $-4.5 \mathrm{pcm} / \mathrm{K}$ for $1200 \mathrm{~K}$ (Fig. 12). Since nuclear data evaluated at reasonable temperatures beyond $1200 \mathrm{~K}$ are not available, the study ends at this temperature, but it would be interesting to determine what happen if the fuel can reach higher temperatures, because the FTC trend is to increase and take positive values from approximately $1650 \mathrm{~K}$ upwards (Fig. 12).

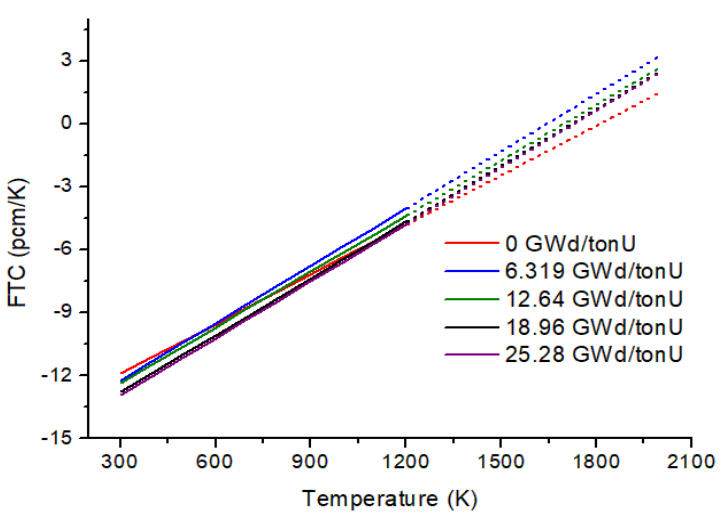

Fig. 12. FTC dependence on temperature from 293.6 to $1200 \mathrm{~K}$ and extrapolated to $2000 \mathrm{~K}$

The MTC and RTC values were calculated between $-5.0 \mathrm{pcm} / \mathrm{K}$ and $-3.5 \mathrm{pcm} / \mathrm{K}$ and between $1.3 \mathrm{pcm} / \mathrm{K}$ and $1.5 \mathrm{pcm} / \mathrm{K}$, respectively. They are reported in Table 13. As can be seen in Fig. 13, as the temperature rises from $293.6 \mathrm{~K}$ to $1200 \mathrm{~K}$, the MTC goes from about $-6.0 \mathrm{pcm} / \mathrm{K}$ to about $-3.0 \mathrm{pcm} / \mathrm{K}$ and the RTC from about $2.7 \mathrm{pcm} / \mathrm{K}$ to about $0.5 \mathrm{pcm} / \mathrm{K}$.

Table 13. MTC and RTC for the five burnup states calculated by two approaches

\begin{tabular}{ccccccc}
\hline \multirow{2}{*}{$\begin{array}{c}\text { Burnup } \\
\text { state }\end{array}$} & \multicolumn{2}{c}{$\begin{array}{c}\text { Linear dependence on temperature } \\
\text { (constants for equation 2) }\end{array}$} & \multicolumn{2}{c}{$\begin{array}{c}\text { Constant value } \\
(\mathbf{p c m} / \mathbf{K})\end{array}$} \\
\cline { 2 - 7 }$(\mathbf{G W d} / \mathbf{t U})$ & \multicolumn{2}{c}{ Moderator } & \multicolumn{2}{c}{ Reflector } & Moderator & Reflector \\
\cline { 2 - 7 } & $\boldsymbol{a}$ & $\boldsymbol{b}$ & $\boldsymbol{a}$ & $\boldsymbol{b}$ & & \\
\hline 0 & 0.00206 & -5.1075 & -0.00168 & 2.5582 & -3.5763 & 1.3027 \\
6.319 & 0.00366 & -6.3694 & -0.00252 & 3.3006 & -3.6358 & 1.4126 \\
12.64 & 0.00252 & -5.9845 & -0.00256 & 3.3190 & -4.1106 & 1.4025 \\
18.96 & 0.00306 & -6.7790 & -0.00212 & 3.0809 & -4.4921 & 1.4936 \\
25.28 & 0.00480 & -8.5710 & -0.00184 & 2.7780 & -4.9856 & 1.4066 \\
\hline
\end{tabular}

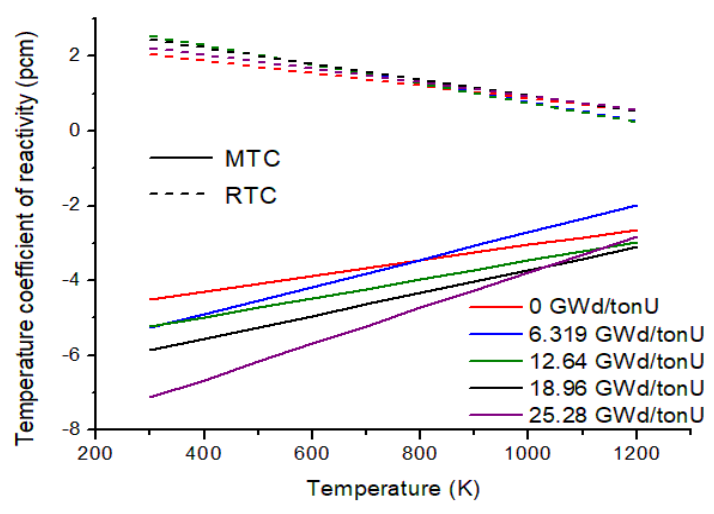

Fig. 13. MTC and RTC dependence on temperature from 293.6 to $1200 \mathrm{~K}$

Figure 14 shows the variation of the temperature coefficients with the fuel burnup state. The RTC remains approximately constant over the fuel burnup. The FTC and the MTC present an increase of $6.2 \%$ and $32.4 \%$ from the fresh fuel state, respectively. The joint effect of the three components in the reactivity feedback was measured through the isothermal temperature coefficient (ITC), shown in Fig. 14. The relatively high modular values of the FTC and MTC cause the ITC to be even more negative despite having a positive RTC. That is to say, an increase in the temperature of reflector induces fewer neutrons to be absorbed by the graphite and more thermal neutrons to return to the core, increasing reactivity; however, the Doppler broadening effect in the fuel and the thermal neutron spectral shift in the moderator are more influential. Similar results were obtained by J. L. Kloosterman et al. [18] for a fluidized bed reactor.

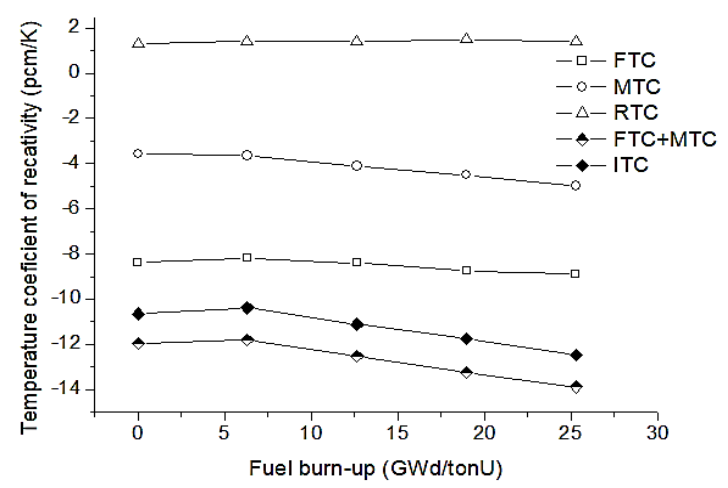

Fig. 14. Contribution of each component's temperature coefficient to the ITC as a function of fuel burnup state 
The ITC considers that fuel, moderator and reflector change their temperature isothermally. Actually, the reflector is away from the core, the heat source; for this reason, this component should not undergo large temperature changes. Then, the temperature coefficient of reactivity, and therefore the reactivity changes by temperature or power variations, will be determined by the contribution of fuel and moderator temperature coefficients. This is added to the fact that the calculated RTC is already small in comparison to the FTC and MTC. A more realistic temperature coefficient of reactivity of the VHTR core is plotted in Fig. 14, representing the algebraic sum of FTC and MTC. This value increases from about $-12 \mathrm{pcm} / \mathrm{K}$ with fresh fuel to about $-13.9 \mathrm{pcm} / \mathrm{K}$ after $25.28 \mathrm{GWd} / \mathrm{tU}$ of fuel burnup. As shown in previous papers, it is undoubtedly the variations that occurred in the fuel composition the main responsible for the differences observed in the reactivity coefficients with the increase in burning. Such variations include not only the consumption of the initially-loaded fissile fuel, but also the generation of new isotopes

Several calculations were carried out with fuel and moderator at $1200 \mathrm{~K}$ to estimate the fission product poisoning by accumulation of the most important isotopes. Figure 15 shows the mass variation of the fission products ${ }^{135} \mathrm{Xe}$ and ${ }^{149} \mathrm{Sm}$ during the burnup cycle of the VHTR model. The mass of ${ }^{135} \mathrm{Xe}$ in the VHTR core reached equilibrium at approximately two days with at about 0.47 grams, while the mass of ${ }^{149} \mathrm{Sm}$ tend to get the equilibrium level (3.0-3.2 grams) after approximately 50 days.

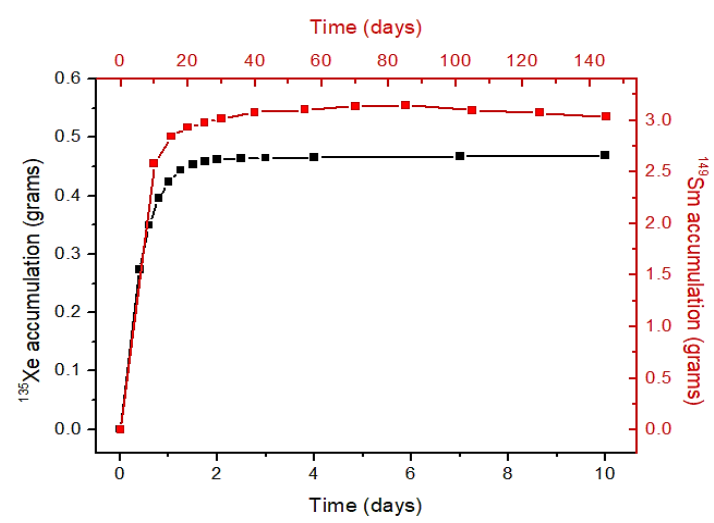

Fig. 15. Accumulation of the fission product ${ }^{135} \mathrm{Xe}$ and ${ }^{149} \mathrm{Sm}$ during the burnup cycle of the VHTR model

Figure 16 shows the evolution of the $K_{\text {eff }}$ with the burnup of the fuel with and without considering the production of ${ }^{135} \mathrm{Xe}$ and ${ }^{149} \mathrm{Sm}$. After the first burnup state ( 33 days), the ${ }^{135} \mathrm{Xe}$ concentration has reached the equilibrium, but the ${ }^{149} \mathrm{Sm}$ mass is yet accumulating, for this reason the $K_{\text {eff }}$ is almost the same for the black and blue curves in $6.319 \mathrm{GWd} / \mathrm{tU}$. After the second burnup state the two isotopes concentration has equilibrated.

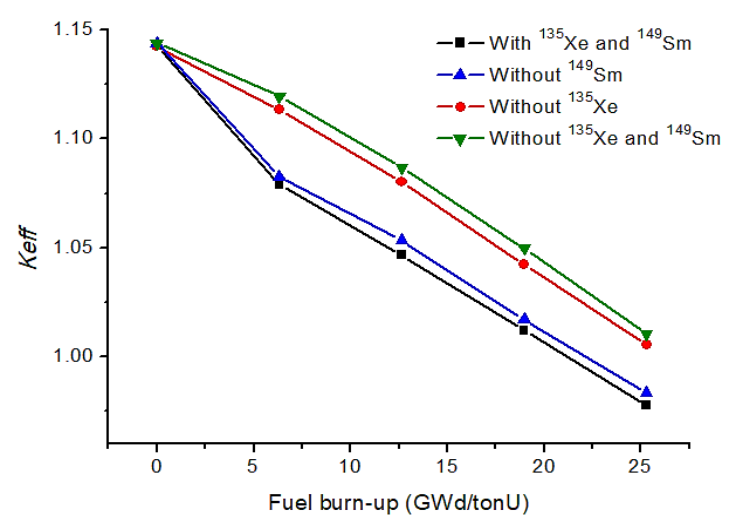

Fig. 16. Evolution of the $K_{\text {eff }}$ with the burnup of the fuel with and without considering the production ${ }^{135} \mathrm{Xe}$ and ${ }^{149} \mathrm{Sm}$

Although the accumulated mass of ${ }^{149} \mathrm{Sm}$ after $25.28 \mathrm{GWd} / \mathrm{tU}$ of fuel burnup is more than six times the accumulated mass of ${ }^{135} \mathrm{Xe}$, the higher absorption cross-section of the second one causes it to introduce $-2904 \mathrm{pcm}$ while the ${ }^{149} \mathrm{Sm}$ production inserts -587 pcm of reactivity. The combined effect of both fission products implies an average reactivity of $-3475 \mathrm{pcm}$.

\section{CONCLUSIONS}

The viability of the utilization of the MCNP6 code and the developed models for the study of the physics of the VHTR core was confirmed through the calculation of benchmarks announced by the IAEA (IAEA-TECDOC-1249, 2001 and IAEATECDOC-1694, 2013). Results obtained show that the code and the developed models present a good agreement with the experimental results.

Neutronics calculations of the VHTR model were made for five fuel burnup states: 0, 6.32, 12.64, 18.96, and $25.28 \mathrm{GWd} / \mathrm{tU}$. The parameters studied were the $K_{\text {eff }}$ and the mass variations of the fission product ${ }^{135} \mathrm{Xe}$ and ${ }^{149} \mathrm{Sm}$.

The fuel, moderator, and reflector temperature coefficients of reactivity were estimated in the ranges between $-9 \mathrm{pcm} / \mathrm{K}$ and $-8 \mathrm{pcm} / \mathrm{K}$, between $-5.0 \mathrm{pcm} / \mathrm{K}$ and $-3.5 \mathrm{pcm} / \mathrm{K}$ and between $1.3 \mathrm{pcm} / \mathrm{K}$ and $1.5 \mathrm{pcm} / \mathrm{K}$ and, respectively, for all the fuel burnup states. Also, the three coefficients were reported as a linear function of temperature, where all they decrease from $293.6 \mathrm{~K}$ to $1200 \mathrm{~K}$. The combined effect was calculated with the isothermal temperature coefficient of reactivity, however, neglecting the reflector contribution it was estimated a more negative temperature coefficient of 
the VHTR model of about $-12 \mathrm{pcm} / \mathrm{K}$ and slightly increasing with fuel consumption. These parameters demonstrate an important safety feature of this VHTR design.

The mass of ${ }^{135} \mathrm{Xe}$ in the VHTR core reached equilibrium at approximately two days at about 0.47 grams, while the mass of ${ }^{149} \mathrm{Sm}$ tended to reach the equilibrium level (3.0-3.2 grams) after approximately 50 days. The production of ${ }^{135} \mathrm{Xe}$ and ${ }^{149} \mathrm{Sm}$ implied a reactivity of $-2904 \mathrm{pcm}$ and $-587 \mathrm{pcm}$, respectively. The combined effect of both fission products implied a reactivity of $-3475 \mathrm{pcm}$.

\section{ACKNOWLEDGMENT}

This research was partially supported by the Conselho Nacional de Desenvolvimento Científico e Tecnológico do Brasil (CNPq), projects no: 141270/2016-0 and 142409/2016-2.

\section{AUTHOR CONTRIBUTION}

D.M. Pérez and L.P.R. Garcia conceived the presented idea, developed the theory, and wrote the manuscript. L.H. Pardo and D.M. Pérez performed the computational calculations. D.E.M. Lorenzo and C.A.B. de Oliveira Lira supervised the findings of this work.

\section{REFERENCES}

1. OECD/NEA, Technology Roadmap Update for Generation IV Nuclear Energy Systems, OECD Nuclear Energy Agency for the generation IV International Forum, Paris (2014)

2. IAEA, Guidance on Nuclear Energy Cogeneration, IAEA, Vienna (2019).

3. GIF, R\&D Outlook for Generation IV Nuclear Energy Systems: 2018 Update, GIF (2019). https://www.gen-4.org/gif/upload/docs/applica tion/pdf/2019-06/7411_gif_r_and_d_outlook_ update_web.pdf.

4. B. Zohuri, Generation IV nuclear reactors, in: Nuclear Reactor Technology Development and Utilization, S.U-D. Khan and A.V. Nakhabov (Eds.), Elsevier (2020) 213.
5. Z. Zhang, Y. Dong, F. Li et al., Engineering 2 (2016) 112.

6. M.A. Fütterer, G. Strydom, H. Sato et al., The High Temperature Gas-Cooled Reactor, Elsevier (2020).

7. Q. Sun, W. Peng, S. Yu, et al., Nucl. Eng. Des. 360 (2020) 110477.

8. X. Qu, G. Zhao and J. Wang, Int. J. Hydrogen Energy. (2020) in Press.

9. H.D. Gougar, D.A. Petti, P.A. Demkowicz et al., Nucl. Eng. Des. 358 (2020) 110397.

10. Los Alamos National Laboratory, MCNP6.1/MCNP5/MCNPX User Manual, Los Alamos National Laboratory, Los Alamos (2013) 1001.

11. IAEA, Critical experiments and reactor physics calculations for low enriched high temperature gas cooled reactors, IAEA, Vienna (2001).

12. IAEA, Evaluation of High Temperature Gas Cooled Reactor Performance: Benchmark Analysis Related to the PBMR-400, PBMM, GT-MHR, HTR-10 and the ASTRA Critical Facility, IAEA, Vienna (2013).

13. C. García, J. Rosales, L. García et al., Prog. Nucl. Energ. 66 (2013) 61.

14. J. Rosales, A. Muñoz, C. García et al., International Journal of Nuclear Energy 2014 (2014) 1.

15. L.P. Rodriguez, D. Milian, C.R. García et al., Atom Indonesia 41 (2015) 53.

16. P.G. Rousseau, C.G. Du Toit and H.J. Van Antwerpen, CFD and Systems ThermalHydraulic Analysis in the Design and Safety Assessment of High-Temperature Reactors, in: Advances in Computational Fluid Dynamics in Nuclear Reactor Design and Safety Assessment, J.B. Joshi, A.K. Nayak (Eds.), woodhead Publishing Series in Energy, Elsevier (2019) 755.

17. J.J. Duderstadt and L.J. Hamilton, Nuclear Reactor Analysis, John Wiley \& Sons, Inc., New York (1976).

18. J.L. Kloosterman, V.V. Golovko, H. van Dam et al., Nucl. Sci. Eng. 139 (2001) 118. 